\title{
The social patterning of teenage pregnancy
}

Teenage pregnancy has been viewed with increasing concern in recent years. In the United Kingdom, the issue became a public health priority through the incorporation of targets for reducing teenage pregnancy in the "Health of the Nation" strategy. ${ }^{1}$ The continuing political importance of teenage pregnancy is marked by the current government's decision to commission a report by its Social Exclusion Unit. Although the UK has the highest teenage fertility rate in Europe, the perception of teenage pregnancy as an increasing problem is false; the live birth rate to teenage women in the UK in 1987 was 30.9/1000 compared with $49.7 / 1000$ in $1970 .^{2}$

Health concerns have focused on the medical risks to the young mother and her infant. Teenage women have been reported at increased risk of pregnancy complications, postnatal depression and, if married, of early marital breakdown. ${ }^{3}$ Children of teenage mothers have a higher risk of adverse perinatal and later childhood outcomes. However, when confounding by socioeconomic status is properly accounted for, differences in perinatal outcome disappear ${ }^{4}$ and successful parenting is more dependent on adequate material resources and social support than maternal age. ${ }^{5}$

Teenage pregnancy and teenage mothering show social gradients in the expected direction with high rates associated with high levels of deprivation. However, the gradient is much less marked for conception than it is for childbearing with a much higher abortion rate among more socially advantaged teenage women. ${ }^{6}$ Andrew McCulloch's paper in this issue of the journal ${ }^{7}$ confirms the gradient and contributes to the debate on the relative strength of individual and area level factors in determining social gradients in health. Using the $2 \%$ sample of anonymised records (SAR) from the 1991 census linked with area data from districts of residence identifiable in the SAR, his results show an association between non-marital teenage childbearing and residence in deprived areas that is largely attributable to personal disadvantage. The effects of area independent of individual level disadvantage are small.

McCulloch's findings are consistent with work implicating individual level economic factors in teenage childbearing. A study based on the OPCS (now ONS) Longitudinal Study suggested that unemployment might be causally related to teenage childbearing as young unemployed women aged 17-19 years in 1981 were more likely than those who were employed or in full time education to become mothers in the years following the 1981 census. ${ }^{8}$ It has been suggested that being a mother may be seen as a "job description" for young women with no employment prospects. $^{8}$

McCulloch's paper is a further contribution to the debate on health inequalities and explanations for social gradients. His findings tend to support the neo-materialist explanations for social gradients in health advanced by Lynch et al against explanations based on social capital and social coherence. ${ }^{10}$ The debate is not a sterile academic exercise but has major health and social policy implications. If personal material disadvantage appears to have a stronger association with teenage childbearing than area disadvantage then health and social policy should be directed primarily at alleviating personal disadvantage rather than focusing on strengthening area level characteristics such as social capital.

However, inequalities and social gradients in different health outcomes will not necessarily all be sensitive to the same social and health policy changes. Health inequalities research should continue to clarify the determinants and mediators of specific outcomes. While McCulloch's findings suggest that individual level measures account for much of the area level differences in teenage childbearing, area level measures of socioeconomic status remain useful tools for studying social gradients and, for some outcomes, may be preferable to individual level measures such as the Registrar General's social class. ${ }^{11}$

NICK SPENCER

Department of Applied Social Studies/School of Postgraduate Medical Education, University of Warwick, Coventry CV4 7AL, UK

(n.j.spencer@warwick.ac.uk)

1 Department of Health. The Health of the Nation: a strategy for health in England. London: HMSO, 1992.

2 Peckham S. Preventing unintended teenage pregnancies. Public Health 1993;107:125-33.

3 Bury J. Teenage pregnancy in Britain. London: Birth Control Trust, 1984.

4 Zuckerman B, Alpert JJ, Dooling E, et al. Neonatal outcome: is adolescent pregnancy a risk factor? Pediatrics 1983;71:489-93.

5 Gregnancy a risk factor? Pediatrics 1983;71:489-93.

6 Smith T. Influence of socioeconomic factors on attaining targets for reducSmith T. Influence of socioeconomic factors on at
ing teenage pregnancies. BMF 1993;306:1232-5.

7 McCulloch A. Teenage childbearing in Great Britain and the spatial concentration of poverty households. F Epidemiol Community Health 2001; 55:16-23.

8 Penhale B. Associations between unemployment and fertility among young women in the early 1980s. Longitudinal Study Working Paper no.60. London: OPCS, 1987.

9 Lynch JW, Davey Smith G, Kaplan GA, et al. Income inequality and mortality: importance to health of individual income, psychosocial environment, or material conditions. BMF 2000;320:1200-4.

10 Kawachi I, Kennedy BP, Locher K, et al. Social capital, income inequality and mortality. Am $\mathcal{F}$ Public Health 1997;87:1491-8.

11 Spencer NJ, Bambang S, Logan S, et al. Socioeconomic status and birth weight: comparison of an area-based measure with the Registrar General's social class. $\mathcal{f}$ Epidemiol Community Health 1999;53:495-8. 